DE DE GRUYTER

OPEN

Polish Cartographical Review

Vol. 48, 2016, no. 2, pp. 55-66

DOI: $10.1515 /$ pcr-2016-0005

TADEUSZ PASTUSIAK

Gdynia Maritime University, Faculty of Navigation

tadeusz.pastusiak@wp.pl

\title{
Consistency of data presented on modern maps of ice cover in the Arctic
}

\begin{abstract}
Information about the condition of ice cover on surface of the water, which are the content of map, are important for carrying out safe navigation and efficient economic activity in the polar regions. Methods of mapping can be fully automated on the basis of developed through years of experience algorithms or additionally supported by experienced professionals. The content of some of those now commonly encountered maps is compiled on the basis of mixed methods. In this work geographic positions of ice maps content are analyzed taking into consideration their usefulness for planning ship's voyage in ice. The results of this work allow using the contents of studied maps for determining the ship's route in ice and voyage planning of the ship in ice according to her hull strengthening.

The ice maps often have boundary lines for different values of reference. The maximum width of the strips of each boundary line within the Marginal Ice Zone is $100 \mathrm{~km}$. The mean square error of position of the analyzed maps is $+/-2.0 \mathrm{~km}$. Average locations of boundaries are consistent except for GRIB type maps of the OSI SAF and NIS, which seem to indicate much lower value of ice floe concentration. The NIC MIZ maps and S-411 standard maps are consistent for the $13 \%$ and $81 \%$ concentration. The $40 \%$ limits on MASIE maps and $46 \%$ limits of concentration on S-411 standard maps are also consistent. The course of ice edge issued by the NIS for the GMDSS METAREA, 19 region visualizes well the boundaries of the area where the ship might encounter any form of ice. Information of the GMDSS METAREA 20 region issued by the AARI represents the average of the limits 1 to $46 \%$ of all sources of information, and on average the $13 \%$ limit of ice concentration. The one-year old ice limit with thickness of 0.10 to 0.30 meters on the AARI map is consistent with course and average location of boundaries of $81 \%$ ice concentration on the NIC MIZ map and S-411 standard map. The multi-year old ice limit of thickness from 0.30 to 2.00 meters on the AARI map is coincident with the $79 \%$ limit of concentration displayed on the NIS map.
\end{abstract}

Keywords: ice map content, S-411 standard, remote sensing, safety of sea transport, ice navigation

\section{Introduction}

Information about the state of ice cover are important for safe navigation and efficient economical activity in the polar regions. Over the years, evolved methods of obtaining information (A.R. Mahoney et al. 2008, https://earthdata. nasa.gov/user-resources/remote-sensors, accessed 5.03.2016). Since 1933 are conducted visual observations at meteorological polar stations, ships and aircraft ice reconnaissance. Primary aircraft ice reconnaissance based on visual observations; since 1951 photographs were used. In the years 1964-1990 instrumental recordings were used. In the years 1968-1992 were used SLAR radar methods. In the years 1953-1972 measurements were obtained using buoys of the DARMS project and since 1979 based on project IABP. The research of ice cover by the methods of satellite remote sensing were launched in 1966 in visible band, from 1972 in infrared band and from 1996 by the SAR methods. The SAR method seems at the moment to provide the best resolution, which in recent years already reaches 50 meters. However, the quality of the information presented on the ice cover maps was much better if the process of analyzing the data sources has been controlled and corrected by experienced analysts. The best results were achieved by 
the additional verification of automatically obtained data with these of terrestrial observations.

The original form of communication was voice message. Then the paper maps distributed via facsimile devices by cable (terrestrial) or radio. Later paper maps recorded in the form of digital raster BMP, GIF, JPG, JPG2000, TIFF, PNG, PDF or EPS file formats. Then implemented digital georeferenced raster maps of GeoTIFF and GeoPDF type.

Simultaneously were created gridded and vector maps. In the gridded GRIB type files the single point information concerns the geographic position (longitude and latitude) or contractual grid ( $X$ and $Y$ coordinates). In the gridded NetCDF type files is contained additional information about the quality and reliability of the contained data. In the gridded HDF file type the information about position coordinates is contained in separate files. The basic portrayal of the gridded information is a mosaic grid with defined side dimensions. The scale of the ice cover characteristics is discrete. Software for visualization of gridded data can interpolate values between the grids. The method of interpolation may not be notified to the user. Thus obtained continuous scale of ice cover characteristics is only interpolation performed by software and does not reflect the actual state.

Vector files type ESRI Shape (SHP, SHX, DBF, PRJ) and KMZ contain spatial information about the state of ice cover. Series of points with defined coordinates is related to area of the same characteristics value. Using the software can see a preview of more detailed information (figs. 3 and 6). ESRI Shape files can have imposed formal content according to standard SIGRID, SIGRID-2 or SIGRID-3 in successive versions 1, 2 i 3 (WMO 2007). It can be assumed that the actively developing S-411 standard (IHO 2014) of electronic navigational charts illustrating the condition of sea ice cover in GML format is a continuation of the development and standardization of maps of the ice cover on water. Previous work of the author of a similar nature (T. Pastusiak 2015) included other existing in 2009 set of maps. Vector files were SIGRID-3 standard version 1. Now, research was conducted for the same region of the Arctic north of Svalbard. The research region included the area bounded by coordinates $75^{\circ} \mathrm{N}$ to $85^{\circ} \mathrm{N}$ and longitude of $0^{\circ} \mathrm{E}$ to $70^{\circ} \mathrm{E}$. Not all files are published daily. In or- der to be consistent with the time, the files issued on 25 March 2016 were analyzed. The exception is one file published on 23 February 2016 and one raster file issued once a month (from 2 February 2016).

The objective of study is to assess the consistency of information on position coordinates of sea ice cover characteristics contained on contemporary maps available on the Internet. During the research is planned to answer a few questions:

1. What is the accuracy of the position presented by the sources of information?

2 . Is the position of the characteristics of the ice cover and the concentration of ice floe limits contained in various forms of message and data storage consistent?

3. What place among the previously existing data sources occupies a new IHO S-411 map standard of state of ice cover in GML format (IHO 2014) intended for the navigation of ships in ice?

The most frequently reported type of information on the condition of ice cover is the concentration, i.e. the proportion of area of the ice covering the sea. It is depicted both in the full-scale of ten discrete or continuous scale in simplified Mariginal Ice Zone (MIZ) form or in the form of ice boundary of a certain compactness (concentration). The highest interest in the concentration of ice resulting from the character of MIZ zone. Boundary of the ice indicates the areas accessible to ships not designed for navigation in ice (no ice class). Generally, it refers to ice concentration of $10-15 \%$. Areas with a concentration of ice from 0 to $60 \%$ are used to navigation for vessels of different ice class (T. Pastusiak 2010). Ships of the weakest reinforcements of the hull (ice class L4) may, in accordance with safety regulations navigate in ice of concentration from 10 to $30 \%$. Ships with average reinforcements of the hull (ice class L1 to L3 and the UL class) may navigate in ice of concentration from 40 to $60 \%$. Areas of concentration of ice from $70 \%$ upwards are eligible to navigate for icebreakers and ships of a high ice class with the assistance of icebreakers.

In the MIZ zone are sought opportunities to extend the navigation season significant due to the transport of goods and the exploitation of natural resources of the sea and coastal areas under water and on land. Because the 
concentration limit of $80 \%$ is more common than the limit of $70 \%$, boundary concentration $80 \%$ was admitted to study. Therefore, during the analysis has been paid particular attention to the limits of ice floe concentration at 15,40 and $80 \%$.

\section{Characteristics of data sources}

Among the many available online sources of information about the state of the ice cover the files which takes WMO or IHO for use in shipping were selected (WMO 2000, 2005, 2010/1, 2010/2; IHO 2014). Most of them are disseminated in the GMDSS system or on the JCOMM website. These are:

1. Maps of ice concentration, age and form of ice, and many other detailed information for the selected regions of the Arctic Ocean of the ESIMO project (fig. 1) in raster GIF format (http:// www.bsis-ice.de/lcePortal/Metareas.html, accessed 16.03.2016). These are developed on the basis of satellite information (in the visible, infrared and radar bands), and reports from the Arctic and coastal stations, and from ships. Data are collected for 2-5 days, and after averaging are issued every Thursday, which is the reference date.

2. Maps of ice concentration, age and form ice on the Arctic Ocean of the AARI in georeferenced vector ESRI Shape format (http://www. aari.ru/projects/ecimo/index.php?im=100, accessed 25.02. 2016). Details of the publication are the same as those described above.

3. Maps of computational predictions (fig. 2) of ice concentration in the Arctic Ocean of the AARI in the form of isolines in raster format (http://ocean8x.aari.nw.ru/index.php?id=600\&model=3, accessed 2502 2016).

4. Maps of age of ice in the Arctic Ocean of the PLANETA project in raster format JPG (http:// planet.iitp.ru/index1.html, accessed 22.02.2016). To develop these maps automatic object classification (cluster analysis) of multispectral satellite data are used. They are based on SAR images from Severyanin satellite.

5. Maps of ice concentration in the European part of the Arctic Ocean of the NIS (fig. 3) in the ESRI Shape vector format (ftp://ftp.dnmi.no/ projects/ICEMAR/general, accessed 28.02.2016). These are developed on the basis of SAR images of European and Canadian RADARSAT and

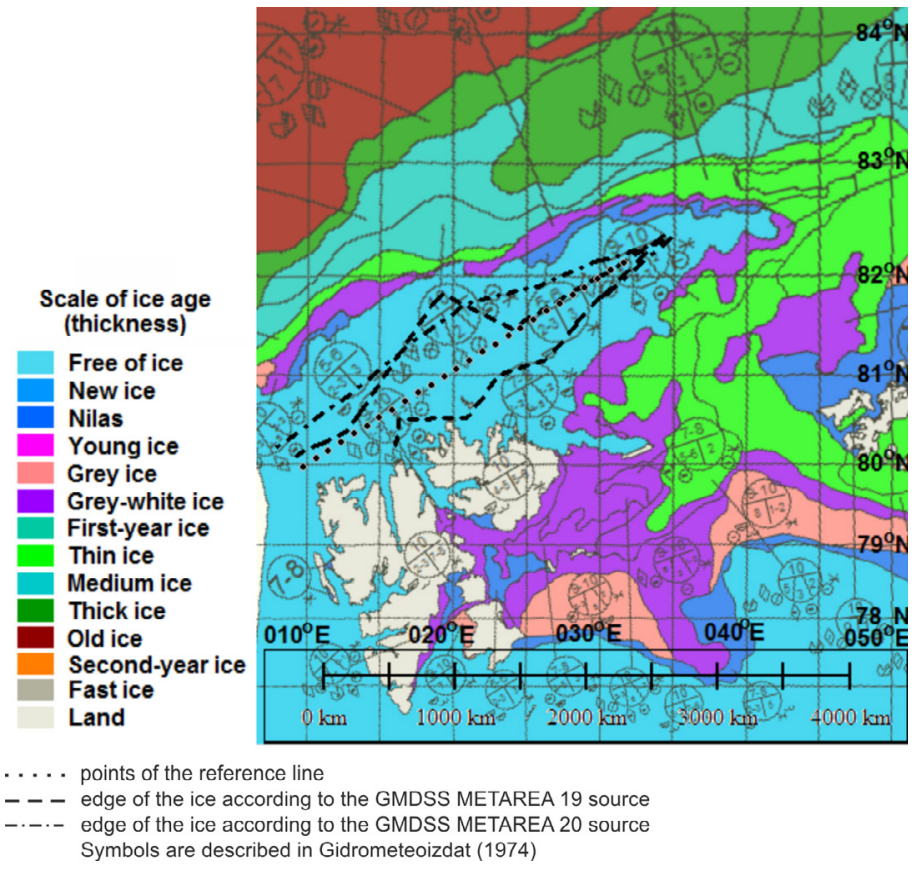

Fig. 1. Map of sea ice of the ESIMO project 


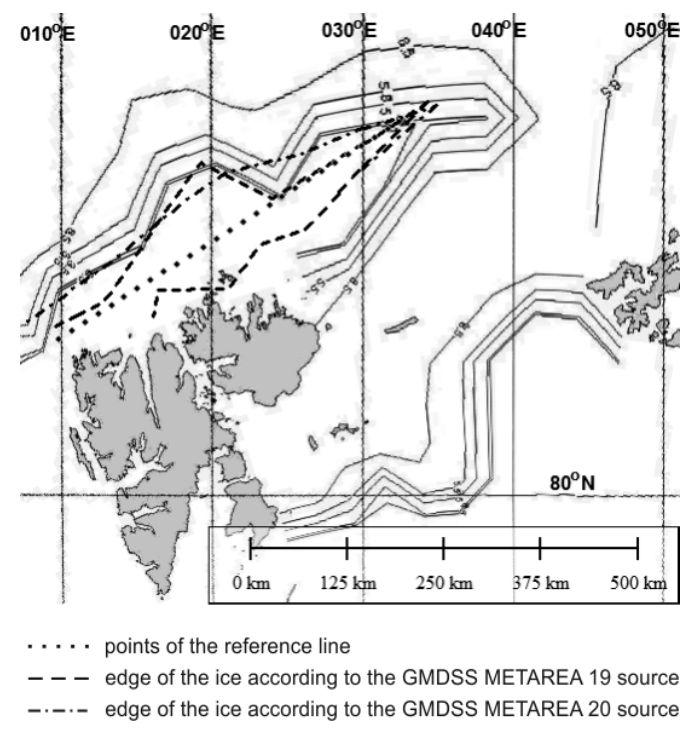

Fig. 2. Map of computational ice concentration of the AARI

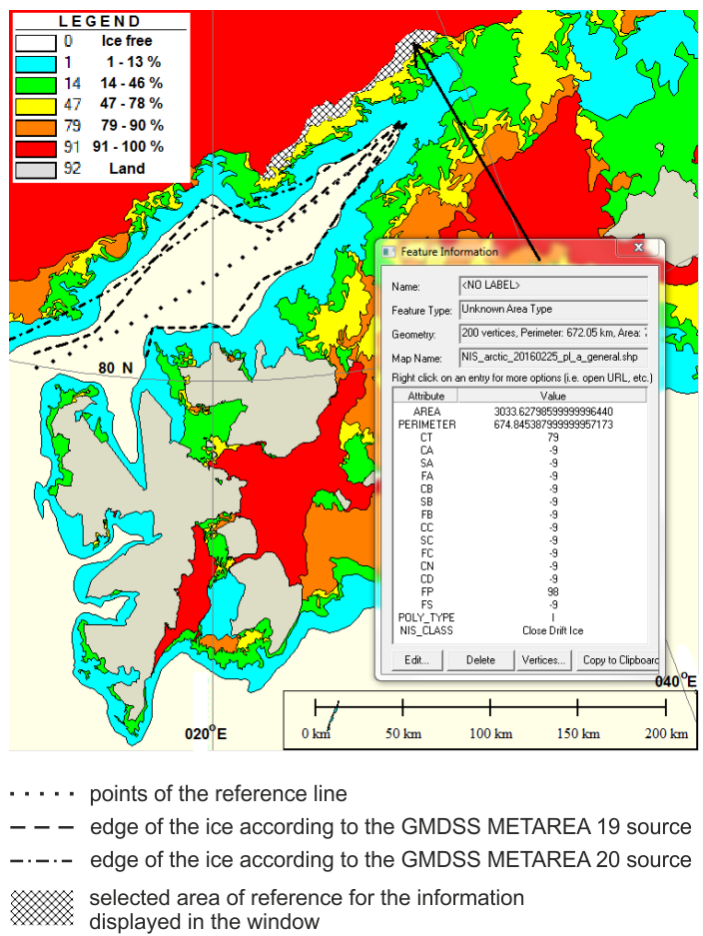

Fig. 3. The map of sea ice of the NIS 
ENVISAT satellites, at a resolution of $75-150$ meters. The spatial resolution of the map is equal to $1,000 \mathrm{~m}$.

6. Maps of ice concentration in the Arctic Ocean of the OSI SAF in georeferenced gridded GRIB format (fig. 4 and fig. 5) in a grid resolution of $0.25^{\circ}$ latitude by $0.25^{\circ}$ of longitude (ftp://ftp.dnmi.no/projects/icecharts, accessed 26.02.2016). They are calculated from adjusted color temperatures SSMIS using the linkage of state-of-the-art algorithm.

7. Maps of ice floe concentration in the Arctic Ocean of the NOAA in georeferenced gridded GRIB format with a resolution of the grid 5 minutes latitude by 5 minutes longitude (http://nomads.ncep.noaa.gov/pub/data/nccf/com/omb/ prod/, accessed 25.02.2016). They are done based on the automatic analysis of ice concentration with a reduction of the weather effects (filtering). The satellite information of SSMR, SSMI, AMSR-E, SMI-S, AMSR2 data processing based on the programs Team 1 or Team 2 were successively used.

8. Maps of ice floes concentration in a simplified Marginal Ice Zone scale in the Arctic Ocean of the NIC in georeferenced vector ERSI Shape format (http://www.natice.noaa.gov/products/ daily_products.html, accessed 25.02.2016). They are summarized from various sources with better resolution than 50 meters per pixel. Sources of information include (but not exclusively) ENVISAT, OLS DMSP, AVHRR and RADARSAT. Analysts carry out the necessary interpretation of the images, which increases the value of these sources for the correct identification of the range of the ice edge.

9. Maps of MASIE ice floe concentration limit of $40 \%$ in the Arctic Ocean of the NSIDC in georeferenced vector ESRI Shape format at a grid resolution of $1 \mathrm{~km}$ by $1 \mathrm{~km}$ (http://nsidc. org/data/G02186, accessed 30.03.2016). A variety of data sources, such as MODIS, AVHRR-VIS, GOES, SEVIRI, MTSAT, AMSR-E, SSM/I, AMSU and SAR images of RADARSAT-2, ERS-2, ALOS, PALSAR and ASAR are used when creating these maps. In the absence of direct satellite data the maps of ice concentration and ice edge from the US, Canada, Norway, Denmark, Russia, Germany, Sweden and Japan are also used. They are developed by analysts trained to interpret imaging obtained from satellite remote sensing and climate maps of sea ice.
10. Maps of ice boundary provided by the GMDSS system (figs. 1-6) in clear text by radio or satellite for the METAREA 19 region (http:// weather.gmdss.org/, accessed 25.02.2016).

11. Maps of ice boundary provided by the GMDSS system (fig. 1-6) in clear text by radio or satellite for the METAREA 20 region (http:// weather.gmdss.org/, accessed 2502 2016).

12. Maps of the ice concentration, ice thickness and the size of ice floes analysis of the $\mathrm{NIC}$ for selected regions of the Arctic Ocean of S-411 standard (fig. 6) in georeferenced vector GML format (http://www.bsis-ice.de/lcePortal/ ILP_S411.shtml, accessed 25.02.2016). Previously published maps of this producer were based on the analysis and integration of all available data concerning the ice conditions, including weather and oceanographic information, visual observations from shore, ships and aircraft with airborne radar, satellite images (RADARSAT, ENVISAT, MODIS, GMM) climatic data.

In order to get closer to the methods of mapping can read works of T. Eltoft et al. 2011, R. Erzaty et al. 2007,V.C.R. Jackson and J.R. Apel 2004, P. Rozman et al. 2011,G. Spreen et al. 2006 and H. Sumata et al. 2014.

\section{Assessment of consistency of data on ice cover maps}

It was assumed that the criterion of the accuracy of the position presented by the sources of information is the standard deviation of the characteristic points on the examined maps. One point on Svalbard and one on Franz Josef Land were designated. The standard deviation of the position reached $2.0 \mathrm{~km}$. As a criterion for comparing information about the state of the ice cover the distance of each different ice condition borders from the reference line was adopted. This reference line was running through the center of ice free zone in the analyzed area for the designated 26 points.

The edge of the ice occurrence from the GMDSS source for the METAREA 19 region issued by the NIS shows the lowest distance from reference line with respect to all other groups of information. The METAREA 19 bulletin warns that the specified limit of ice is not intended for navigation. However, can be assumed that this source of information indicates the 


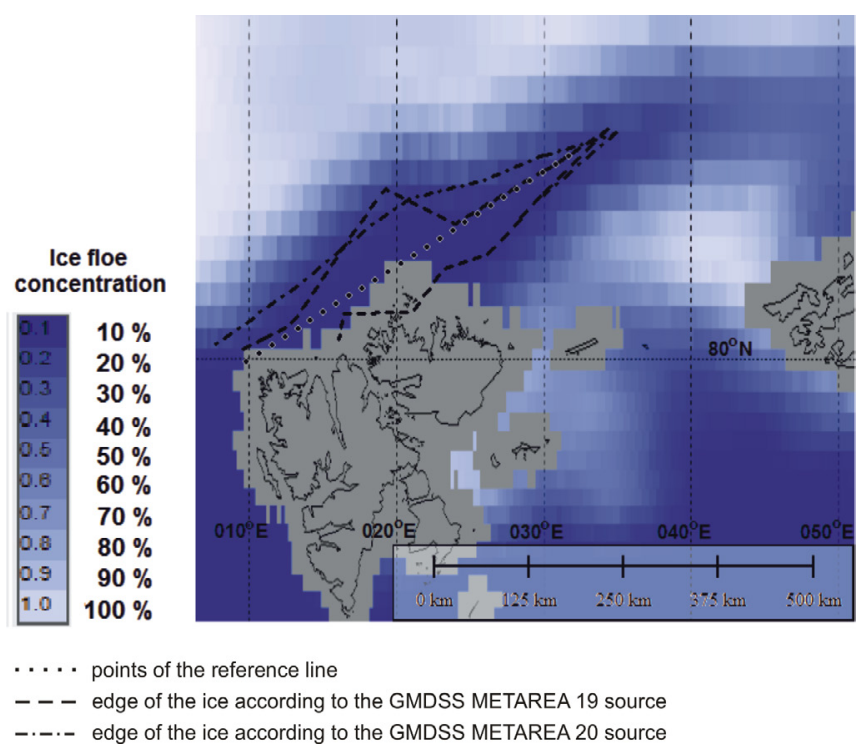

Fig. 4. Map of sea ice concentration in GRIB format (visualization using BallGate GRIB Weather File Viewer Professional software)

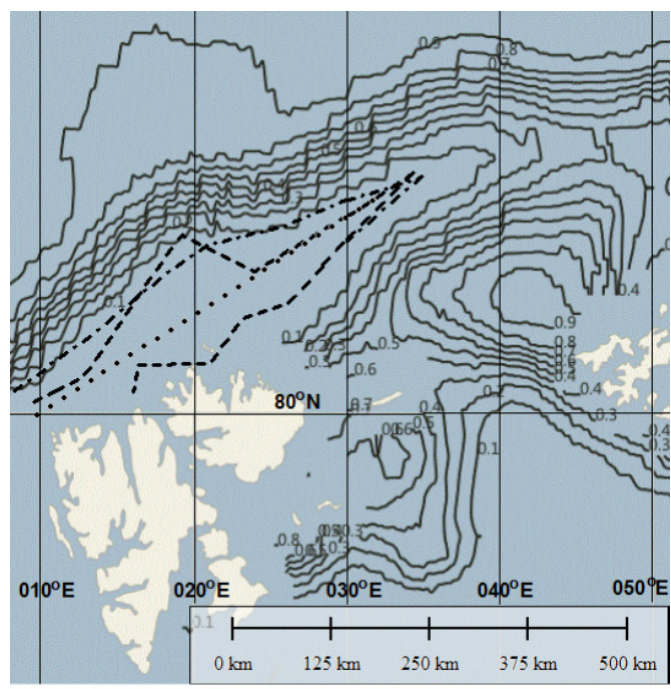

$\ldots$. points of the reference line
--- edge of the ice according to the GMDSS METAREA 19 source
$\ldots-\cdot-$ edge of the ice according to the GMDSS METAREA 20 source

Fig. 5. Map of sea ice concentration in GRIB format (visualization using Meteo Explorer software) 


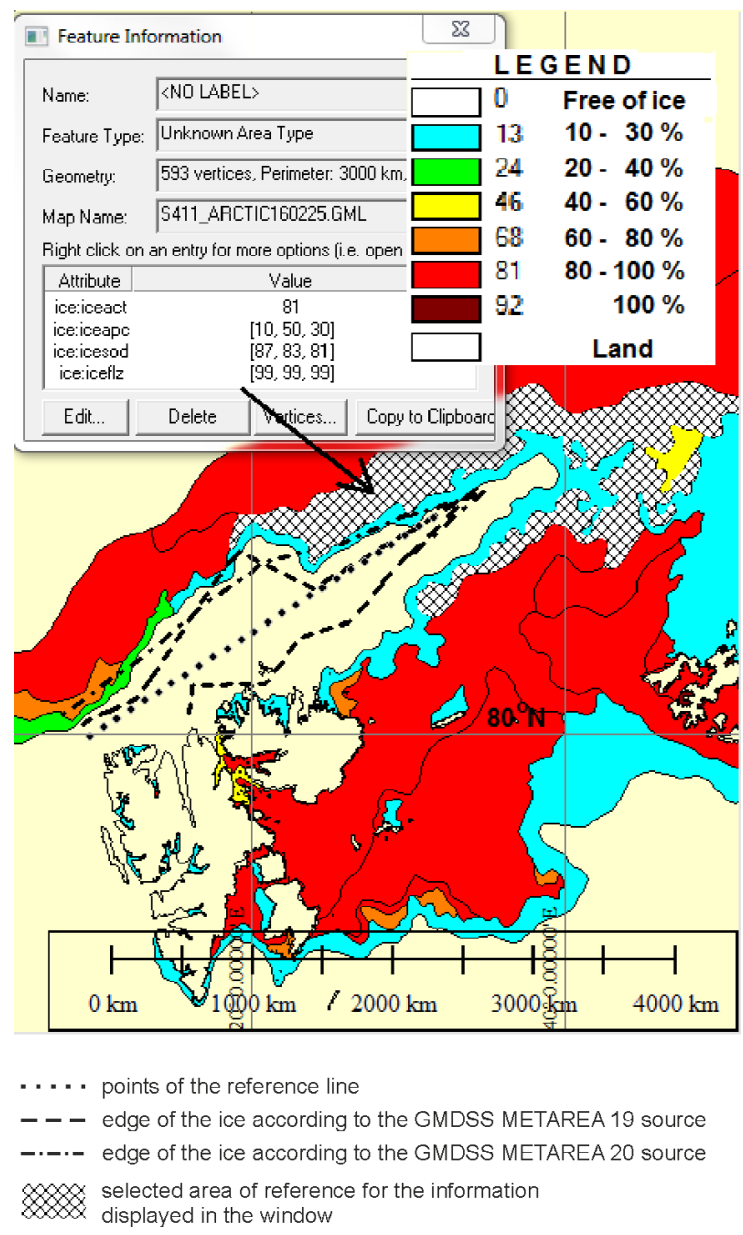

Fig. 6. Map of sea ice in the GML format of S-411 standard

beginning of the possibility of encountering any form of ice. So it sets the boundaries of safe navigation for ships not structurally suitable for navigation in ice and puts the navigator on the safest side. The edge of the ice occurrence is consistent with the concentration limits visualized on the NIS map. In figure 7 is observed the correct sequence of individual distances of boundaries. Meanwhile, the GMDSS ice edge for the METAREA 20 region issued by the AARI is clearly smoothed. The MASIE line for ice concentration of $40 \%$ is inconsistent with the NIS data, because coincides with line of $1 \%$ concentration (NIS).
The spatial distribution of the ice edge issued by the NIS for the GMDSS METAREA 19 region is consistent with the limits of ice concentration presented on the computational AARI map. In figure 8 is shown the correct sequence of individual distances of boundaries. Meanwhile, the ice edge issued by the AARI for the GMDSS METAREA 20 region is clearly smoother and consistent with the limits of 5 and $10 \%$ concentration of the computed AARI map of concentration. Its trend line runs between the trend lines for the 5 and $10 \%$ concentration.

The spatial distribution of the ice edge issued by the NIS for the GMDSS METAREA 19 


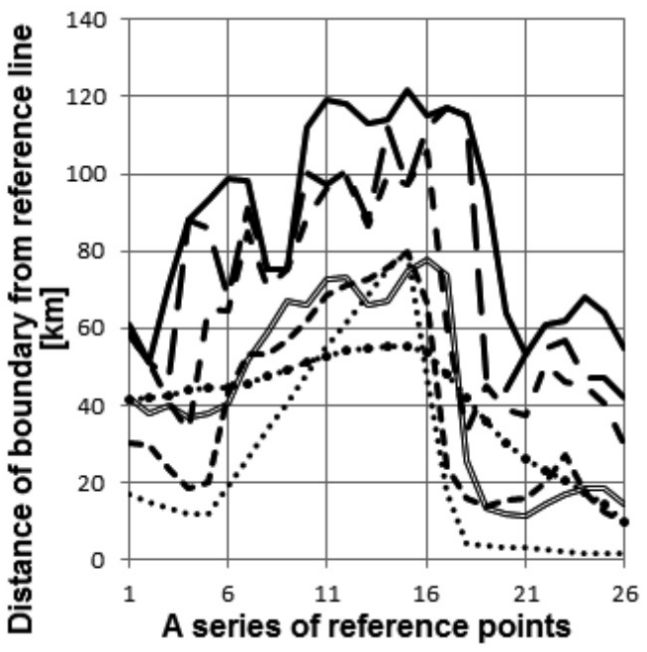

NIS:

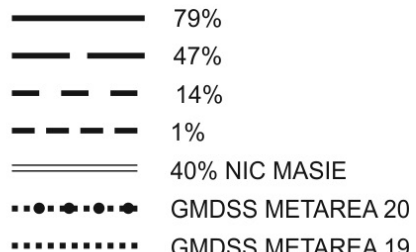

Fig. 7. Distances of boundaries from the reference line (developed by the author)

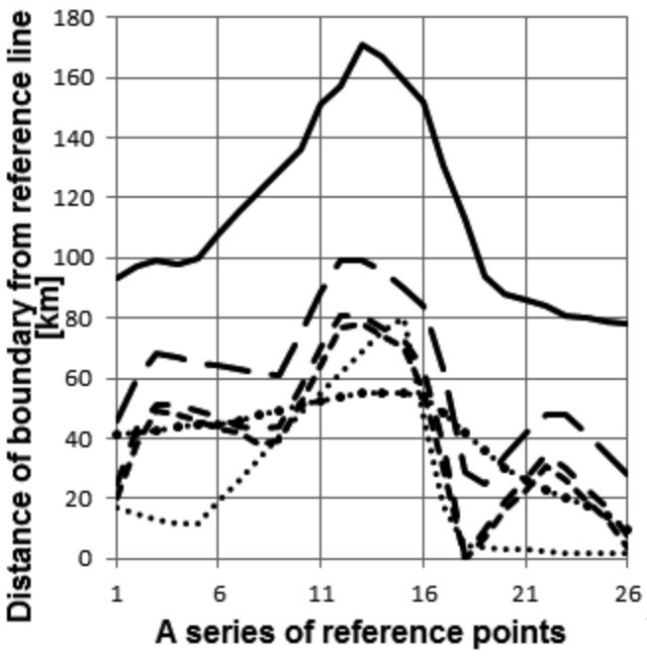

AARI: $85 \%$
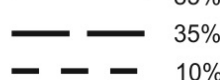

- - $-5 \%$

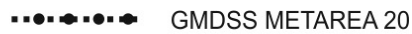

......... GMDSS METAREA 19

Fig. 8. Distances of boundaries from the reference line (developed by the author)

region is also consistent with the limits of concentration presented on new S-411 standard map. In figure 9 is visible the correct sequence of distances for consecutive boundaries. The ice edge for the GMDSS METAREA 20 region issued by the AARI is clearly smoothed. Its trend line coincides with the MASIE trend line for $40 \%$ concentration. The MASIE line is coincident with $46 \%$ concentration edge on the map of new S-411 standard.
Lines of the same concentration in GRIB type files issued by the OSI SAF and NIC are consistent in groups of $10 \%, 40 \%$ and $80 \%$ ice concentration. Groups of $10 \%$ and $80 \%$ are not consistent with other data sources. Only the group of $40 \%$ concentration in GRIB type files issued by the OSI SAF and NIC is consistent with the $79 \%$ limit on map issued by the NIS.

Very high coincidence of distances show the boundaries of the beginning of the occurrence 

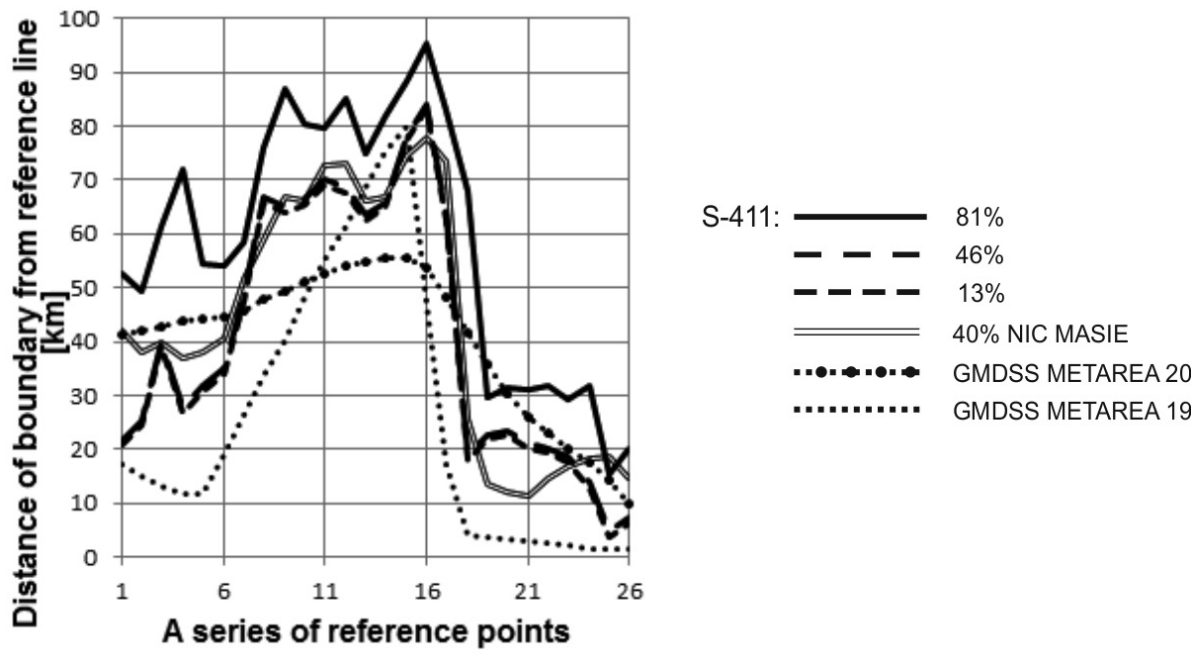

Fig. 9. Distances of boundaries from the reference line (developed by the author)

of ice in most data sources (GMDSS METAREA 20 , NIS $1 \%$, AARI computational 5\%, NIC MIZ $13 \%$, S-411 13\%, S-411 46\%, AARI computational $10 \%$, MASIE $40 \%$ ). Overlapping of ice concentration borders at an average distances $40.4 \mathrm{~km}$ (for medium distances from 38.3 to $43.4 \mathrm{~km}$ ) and the overlapping boundaries concentration 13 and $46 \%$ for the S-411 data source suggests that the belt of ice concentration from 1 to $46 \%$ is very narrow. In fact, width of this belt is on average $22.9 \mathrm{~km}$ with a standard deviation of $9.7 \mathrm{~km}$ (from $9.2 \mathrm{~km}$ to $49.2 \mathrm{~km}$ ). It seems that the GMDSS data source for METAREA 20 region issued by the AARI represents just this group and boundary of average ice concentration equal $13 \%$.

The limits of $13 \%$ and $81 \%$ on the NIC MIZ and S-411 standard maps are consistent. May be assumed that this is due to the development by the same manufacturer (NIC). In fact, the width of the belt for the of concentration $13 \%$ is on average $3.5 \mathrm{~km}$ with a standard deviation of $3.4 \mathrm{~km}$ (from $0.7 \mathrm{~km}$ to $13.3 \mathrm{~km}$ ). The width of ice floe concentration of $81 \%$ is an average of $9.2 \mathrm{~km}$ with a standard deviation of $9.1 \mathrm{~km}$ (from $0.2 \mathrm{~km}$ to $35.3 \mathrm{~km}$ ). It can be assumed that the NIC MIZ files illustrate simplified scale of concentration to indicate the location of the MIZ zone only. A much broader range of concentration scale contain S-411 standard files.

Limit of one-year old ice on the PLANETA maps is located in the MIZ zone of concentration from 13 to $81 \%$. It should be noted, however, that the limit of ice in the data source has a different trend line than all the other ice boundaries. The course of one-year old ice boundary not fully coincide with the boundaries of ice age (thickness) from another producer (AARI). Limit of one-year old ice with a thickness of 0.1 to 0.3 meters (AARI) coincident with the course and average value of the limits of $81 \%$ ice concentration on the NIC MIZ and S-411 standard maps. Limit of one-year old ice with a thickness from 0.1 to 0.3 meters (AARI) deviates from the average distance for concentration $81 \%$ (NIC MIZ and S-411) by an average of $5.9 \mathrm{~km}$ with a standard deviation of $5.9 \mathrm{~km}$ (from $0.7 \mathrm{~km}$ to $23.3 \mathrm{~km}$ ). It runs out of ice zones outlined by the lines of GMDSS METAREA 19 region, NIS 1\%, NIC MIZ 13\%, S-411 13\%, S-411 $46 \%$ and MASIE $40 \%$.

The limit of multi-year old ice age with a thickness of 0.3 to 2.0 meters (AARI) coincident with a limit of $79 \%$ concentration presented on the NIS map. Its average distance from the reference line is $5 \mathrm{~km}$ higher than $79 \%$ concentration line on the NIS map. Also, the distance 
along the reference line is usually higher than the position of $79 \%$ line on NIS map. It can therefore be assumed that the zone of multi-year old ice is outside the MIZ zone presented by the GMDSS, MASIE, NIC MIZ and S-411 standard maps. The principle complied also for the boundary of ice concentration up to $47 \%$ presented by the NIS map and the limits of ice concentration of 5 and $10 \%$ provided by the computational AARI map.

When consider tendency of data sources to detect local changes in ice cover, the highest "sensitivity" show the NIS and AARI ice concentration computational files. Lower "sensitivity" demonstrate the NIC MIZ, AARI (ESRI Shape) and S-411 maps. The lowest "sensitivity" seem to characterize the GRIB type files. Assumed that the cause is the resolution of data processing and resolution of data obtained from satellite remote sensing adopted by the manufacturer. In order to get closer to the methods of mapping can read works of T. Eltoft et al. 2011, R. Erzaty et al. 2007, V.C.R. Jackson and J.R. Apel 2004, P. Rozman et al. 2011, G. Spreen et al. 2006 and H. Sumata et al. 2014.

In the previous work (T. Pastusiak 2015) based on terrestrial observations from the ship was found the highest compliance with the real ice conditions presented on ice concentration data files in JPG format issued by the NIS and regional maps with egg code in PDF format issued by the NIC. The latter are no longer published. A little less consistency demonstrated files of a simplified MIZ scale issued by the NIC. Currently analyzed NIS file has a very diversified course of the boundary line. The limits portrayed by the S-411 and AARI (ESRI Shape) files are coincident with these lines. Their course seems to be, however, more generalized. The ice boundaries shown on the MIZ map issued by the NIC also coincide with the borders on the NIS map. However, they contain only two values on the ice concentration scale and therefore their content is significantly reduced.

The average width of the lane occupied by the ice boundaries being analyzed is of 100 kilometers (table 1). The boundaries of the lower range of MIZ zone suitable for vessels with medium ice class (ice-strengthened) amounts average to $50 \mathrm{~km}$. The ice boundaries lines that make limit of navigation for ships with high ice classes (reinforcements) occupy a zone of $70 \mathrm{~km}$ wide. The navigator having to make a decision on the choice of route in the ice is with a fait of ambiguity. It is not known which of the map shows the actual situation. The discrepancies concern from 1.5 to 6.7 hours of navigation by a ship with an average speed of 18.5 kilometers per hour (10 knots) across the planned direction of voyage.

\section{Conclusions}

The studied ice cover maps often include boundary lines for different values of reference. Thus, the maximum width of the various ice cover boundaries inside of Marginal Ice Zone is $100 \mathrm{~km}$. Despite this fact, determined relationships in between various boundaries of ice concentration, age and thickness of ice on particular ice cover maps. Results of this study allow to determine the route and planning voyage of particular vessel in ice according to their ice class and hull construction.

The mean square error of position on the analyzed maps is $+/-2.0 \mathrm{~km}$. Average position of the boundaries are consistent except GRIB type maps issued by the OSI SAF and NIS, which seem to indicate too low values of concentration. The NIC MIZ and S-411 maps boundaries for values $13 \%$ and $81 \%$ concentration

Table 1. The bandwidth occupied by selected boundaries at designated ranges of MIZ zone

\begin{tabular}{|c|c|c|c|c|}
\hline $\begin{array}{c}\text { Concentration } \\
\text { range [\%] }\end{array}$ & $\begin{array}{c}\text { Average zone } \\
\text { width [km] }\end{array}$ & $\begin{array}{c}\text { Standard deviation of } \\
\text { the average }[\mathrm{km}]\end{array}$ & $\begin{array}{c}\text { Minimal zone } \\
\text { width [km] }\end{array}$ & $\begin{array}{c}\text { Maximal zone } \\
\text { width [km] }\end{array}$ \\
\hline $00-85$ & 103.7 & 13.4 & 81.4 & 123.2 \\
\hline $00-14$ & 51.7 & 17.6 & 27.9 & 108.7 \\
\hline $35-47$ & 47.5 & 13.6 & 33.3 & 96.1 \\
\hline $79-85$ & 72.0 & 13.8 & 54.0 & 105.3 \\
\hline
\end{tabular}


are consistent. The limits of $40 \%$ on MASIE maps and limits of $46 \%$ on S-411 standard maps are also consistent with each other.

The course of ice edge presented by the NIS for the GMDSS METAREA 19 region is consistent with the concentration limits for the NIS maps, computational AARI maps and the new S-411 standard maps. It seems that it illustrates well the limits of the area where the ship might encounter any form of ice. The edge of the ice shown on the GMDSS METAREA 20 region map issued by the AARI is clearly smooth, consistent with the limits of 5 and $10 \%$ concentration on computational AARI maps. It seems that the GMDSS METAREA 20 region map issued by the AARI represents the limits of 1 to $46 \%$ of all sources of information, and on average the limit of $13 \%$ ice concentration.

Boundary one-year old ice with a thickness of 0.10 to 0.30 meters (AARI) coincident with the course and the average location of boundaries of ice concentration $81 \%$ on the NIC MIZ and S-411 standard maps. It goes out of ice zones provided by the GMDSS METAREA 19 region map, NIS 1\%, NIC MIZ 13\%, S-411 $13 \%$, S- $41146 \%$ and MASIE $40 \%$. The multi-year old ice boundary of thickness from 0.30 to 2.00 meters (AARI) coincident with a limit of $79 \%$ concentration presented on the NIS map. It is outside the MIZ zone presented by the

\section{References}

Eltoft T., Lavergne T., Dinessen F., Ivanova N., Sandven S., Similä M., Eriksson L., Borenäs K., Lindberg A., Håkansson B.I., Saldo R., Buus-Hinkler J., Dierking W., Doulgeris A., Lavergne T., Mäkynen, Cheng B., Similä M., Hughes N., Berg A., Buus-Hinkler J., Ivanova N., Dierking W., 2011, Nordic Workshop on Radar Remote Sensing of Sea Ice, Chalmers University of Technology, Gothenburg, Sweden 11 \& 12 January, 2011, ftp://sidads.colorado.edu/pub/projects/noaa/iicwg/business/Nordic_ WS_Proceedings.pdf, accessed 5.03.2016: 58.

Erzaty R., Girard-Ardhuin F., Croize-Fillon D., 2007, Sea ice drift in the central arctic using the $89 \mathrm{GHz}$ brightness temperatures of the advanced microwave scanning radiometer, Users manual. Laboratoire d'Océanographie Spatiale, Département d'Océanographie Physique et Spatiale, IFREMER: 20.

Gidrometeoizdat, 1974, Nomenclature of sea ice, the symbols for the ice charts [in Russian] (Номенклатура морских карт, условные обозначения для ледовых карт): 77.
GMDSS, MASIE, NIC MIZ and S-411 standard maps, out of the ice concentration limit up to $47 \%$ presented by the NIS map and concentration of ice 5 and $10 \%$ provided by the computational AARI map.

\section{List of acronyms}

AARI - Arctic and Antarctic Research Institute

DARMS - Drifting Automatic Radio Meteorological System

GMDSS - Global Maritime Distress and Safety System

IABP - International Arctic Buoy Programme

IHO - International Hydrographic Office

JCOMM - Joint Technical Commission for Oceanography and Marine Meteorology

MASIE - Multisensor Analyzed Sea Ice Extent

METAREA - A geographical sea area established for the purpose of coordinating the broadcast of marine meteorological information

MIZ - Mariginal Ice Zone

NCEP - National Centers for Environmental Prediction

NIC - US National Ice Center

NIS - National Ice Service

NOAA - National Oceanic and Atmospheric Administration

OSI SAF - Ocean and Sea Ice Satellite Application Facility

SLAR - Side Looking Airborne Radar

WMO - World Meteorological Organization

IHO, 2014, Ice Information Product Specification, JCOMM S-411, Monaco: 47.

Jackson C.R., Apel J.R., 2004, Synthetic Aperture Radar Marine User's Manual. Washington, Department of Commerce, http://www.sarusersmanual. com, accessed 5.03.2016.

Mahoney A.R., Barry R.G., Smolyanitsky V., Fetterer F., 2008, Observed sea ice extent in the Russian Arctic, 1933-2006, "Journal of Geophysical Research", Vol. 113, C11005, doi: 10.1029/2008JC004830.

Pastusiak T., 2015, Ship's route planning in ice infested areas of northern Svalbard following ice charts made by remote sensing methods, Activities in Navigation. Marine navigation and safety of sea transportation, CRC Press, Balkema book, pp. 181-192.

Pastusiak T., 2010, Znak lodowy jako element bezpieczeństwa statków w rejonach polarnych,"Prace Wydziału Nawigacyjnego Akademii Morskiej w Gdyni", Tom 25, pp. 61-70.

Rozman P., Hölemann J. A., Krumpen T., Gerdes R., Köberle C., Lavergne T., Adams S., Girard-Ardhuin F., 
2011, Validating satellite derived and modelled sea-ice drift in the Laptev Sea with in situ measurements from the winter of 2007/2008, "Polar Research", Vol. 30 (2011), http://www.polarresearch. net/index.php/polar/article/view/7218, accessed 5.03.2016.

Spreen G., Kern S., Stammer D., 2006, Utilization of Multiple Satellite Sensors to Estimate Sea Ice Volume Flux through Fram Strait, in Arctic sea ice thickness: past, present \& future, P. Wadhams \& G. Amanatidis (eds.), Climate Change and Natural Hazards series 10, European Commission, Brussels, EUR 22416, http://spreen.info/docs/ SpreenEtAl-2006_EU-Book_ArcticSealceThickness.pdf, accessed 5.03.2016, pp. 176-192.

Sumata H., Lavergne T., Girard-Ardhuin F., Kimura N., Tschudi M. A., Kauker F., Karcher M., Gerdes R., 2014, An intercomparison of Arctic ice drift products to deduce uncertainty estimates, "Journal of Geophys. Res. Oceans”, 119, pp. 4887-4921, doi:10.1002/ 2013JC009724. http://olga.majling.eu/ICE/Suma-
ta-2014-An\%20intercomparison\%20of\%20SIP r. pdf, accessed 5.03.2016: 35.

WMO, 2000, Sea-Ice Information Services in the World. Edition 2000, WMO No. 574.

WMO, 2004/1, WMO Colour Code Standards. WMO/ TD-No. 1215, JCOMM Technical Report No. 24:14.

WMO, 2004/2, WMO Sea-Ice Nomenclature Terminology. WMO/OMM/BMO No. 259, Volume 1, Edition 1970 - 2004: 7.

WMO, 2005, Sea-lce Information Services in the World. Edition 2005, WMO No. 574: 100.

WMO, 2007, SIGRID-3: A Vector Archive Format for Sea Ice Charts. WMO/TD No. 1214, 2004 (with revisions by ETSI-III, March 2007), JCOMM Technical Report No. 23. Geneva: 75. .

WMO, 2010/1, Manual on Codes, International Codes. Volume I, (Annex II to WMO Technical Regulations), Part A - Alphanumeric Codes, WMO No. 306: 462. WMO, 2010/2, Sea-Ice Information Services in the World, Edition 2010, WMO No. 574, Geneva:92. 